\title{
Duplicidade do olhar em Nove noites (2002), de Bernardo Carvalho
}

\author{
Duplicity look in Nove noites (2002), by Bernardo Carvalho \\ MARCUS VINICIUS CÂMARA BRASILEIRO \\ Utah State University - Logan - Utah - Estados Unidos da América
}

a

Resumo: Nove noites (2002) é um dos romances mais premiados dentro do conjunto de obras publicado por Bernardo Carvalho. O romance é uma intervenção ficcional sobre o mistério que se formou em torno da morte do estudante de antropologia americano Buell Quain. Este fato aconteceu em 1939 quando Quain estava fazendo uma pesquisa entre os índios brasileiros Krahôs, no interior do Mato Grosso. O ensaio é uma leitura deste romance na qual se focaliza a relação entre os modos de constituição da realidade e da ficcionalidade. Os recursos retóricos mais próximos de um discurso realista (as cartas, as reportagens jornalísticas, etc.) funcionam, nesta narrativa, de forma paradoxal: em vez de construírem uma representação transparente da realidade, tais recursos ajudam a desmistificar os discursos de "verdade", apontando para o caráter simbólico de todo processo representativo.

Palavras-chave: Literatura brasileira; Pós-colonialismo; Hibridismo cultural; Multiculturalismo; Bernardo Carvalho

\begin{abstract}
Nove Noites (2002) is one of the most important novels published by Bernardo Carvalho. The novel is a fictional account of the mystery surrounding the death of the American Buell Quain, an anthropology student who killed himself among the Krahô indians, in Mato Grosso, in 1939. This essay is a close reading of the novel and seeks to highlight the relationship between reality and fictionality. The rhetorical devices closer to a realistic discourse (letters, newspaper articles, etc.) work in this narrative in a paradoxical way: instead of producing a transparent representation of reality, such features help to demystify the "truth" discourses, pointing to the subjective character of any representative process.
\end{abstract}

Keywords: Brazilian literature; Representation; Cultural hybridism; Multiculturalism

Nenhuma página jamais foi limpa.

Mesmo a mais Saara, ártica, significa.

Nunca houve isso, uma página em branco.

No fundo, todas gritam, pálidas de tanto.

PAULO LEMINSKI

Bernardo Carvalho, diferentemente de outros escritores brasileiros contemporâneos, tais como João Gilberto Noll e Silviano Santiago, traz em sua formação intelectual uma intensa atividade jornalística. Mesmo tendo nascido no Rio de Janeiro em 1960, sua atuação como jornalista se concentrou em São Paulo. Foi editor do suplemento literário "Folhetim" da Folha de S. Paulo e também atuou como correspondente internacional deste mesmo jornal em Londres e Nova York. Estreou literariamente em 1993 com o livro de contos Aberração. Dois anos depois, foi publicado o seu primeiro romance, Onze: uma história (1995). A partir de então, a produção literária de Bernardo Carvalho tem tido um fluxo constante. Os romances seguintes foram: Os bêbados e os sonâmbulos (1996); Teatro (1998); As iniciais (1999); Medo de Sade (2000); Nove noites 
(2002); Mongólia (2003); O sol se põe em São Paulo (2007); O filho da mãe (2009). Com a publicação de Nove noites, Bernardo Carvalho recebeu o Prêmio Telecom de Literatura Brasileira. Com Mongólia, recebeu dois outros importantes prêmios: o prêmio da Associação Paulista de Críticos de Arte de 2003 e o Prêmio Jabuti de 2004, na categoria romance.

A formação jornalística de Bernardo Carvalho sempre esteve presente na sua linguagem artística. Em Nove noites, ele ficcionaliza um fato jornalístico, na medida em que transforma em literatura a viagem do estudante de antropologia americano Buell Quain à aldeia indígena dos Krahô, no estado do Mato Grosso, em 1939. Durante a sua expedição etnográfica, Buell Quain se suicida, deixando em aberto o mistério das razões que o teriam levado a cometer tal ato extremo. Bernardo Carvalho aproveita esse fato como mote de estruturação para seu romance e propõe uma discussão sobre os limites e as possibilidades de narrar a realidade do outro ${ }^{1}$. Este ensaio desenvolve uma análise de Nove noites a partir da colocação em cena de questões relativas ao papel do real e do ficcional na literatura contemporânea. Parto do argumento de que, neste romance, as estratégias de utilização dos recursos estéticos realistas funcionam não mais como uma forma de buscar uma transparência na representação da realidade, mas como um mecanismo de desmistificação de uma concepção ingênua de realidade. Além disso, proponho que o surgimento de Nove noites na cena literária brasileira dá continuidade ao gesto modernista de reivindicação da cultura como um fenômeno socialmente híbrido e filosoficamente errante. Antes, porém, da discussão de Nove noites, gostaria de estabelecer uma reflexão sobre o dilema da representação literária articulada a partir do próprio Bernardo Carvalho.

\section{Dilemas da literatura}

"Demorei a entender que os outros não viam o que eu via nos meus livros" (CARVALHO, 1996, p. 217). Esta é a maneira como Bernardo Carvalho inicia uma reflexão sobre a sua literatura ${ }^{2}$. Em depoimento publicado na revista Literatura e Sociedade (USP), Bernardo Carvalho realiza o desnudamento da sua relação com a literatura,

\footnotetext{
Em Mongólia (2003), sétimo romance de Bernardo Carvalho, o argumento fundamental também gira em torno de outra busca. Desta vez, o romance conta a história do resgate de um fotógrafo brasileiro "perdido" na Mongólia. Como pano de fundo da narrativa, pode-se visualizar a mesma preocupação de Bernardo Carvalho, revelada também no romance anterior Nove noites: a questão da dificuldade de descrever os modos de constituição da cultura do outro. O confronto que se estabelece entre as cosmologias ocidentais e orientais se transforma em um modo de relativizar o nosso próprio entendimento sobre os modos de atribuição de sentido a que somos submetidos em nossa própria cultura.

2 CARVALHO, Bernardo. Minha cegueira. In: Literatura e Sociedade, n. 8, São Paulo: USP/FFLCH/DTLLC, 1996, p. 217-219.
}

entendida como um instrumento de aprimoramento do seu olhar e da sua compreensão do mundo:

[...] Minhas narrativas são formas de imaginar o que não consigo entender. São formas de suprir a minha incapacidade de abstração. A literatura passa a ser uma 'formulação de ideias'. Quando falo em 'formulação de ideias' não estou me referindo à ficção reduzida a meio para transmitir as ideias do autor, como no tradicional 'romance de ideias', mas à literatura como forma de pensar para quem não consegue pensar de outra forma. Não tem nada a ver com a ilustração das ideias prévias do autor. Nem com uma escrita calculista e fria, mas com a conversão de sentimentos e emoções em uma forma de pensar. Uma espécie de mitologia da razão, como se isso fosse possível. Daí talvez o meu gosto por aberrações e paradoxos. Os próprios livros são as ideias. É na literatura que elas se manifestam e ganham forma (op. cit., p. 217).

Esta maneira de fazer uma literatura que dá forma a "aberrações e paradoxos" se constitui, dentro do contexto cultural contemporâneo, em um modo de valorizar a literatura como um espaço de rupturas das formas reificadas de conhecimento às quais as sociedades ocidentais estão submetidas. Aquilo que não se consegue entender pelo poder de abstração da razão, pode ser vivenciado pela experiência artística, que se apresenta como um gesto de experimentação com os limites, tanto das nossas percepções e emoções como das nossas práticas. Daí a possibilidade de se penetrar no domínio da aberração e do paradoxo, termos que parecem ser articulados por Bernardo Carvalho para sugerir este domínio discursivo que subverte os ordenamentos lógicos e as expectativas de leitura.

Nesse sentido, a escrita de Bernardo Carvalho, por mais que se aproxime do real e do verossímil, nunca se constitui como uma escrita realista. Em Nove noites, Bernardo Carvalho lança mão de estratégias de verossimilhança que, ao invés de aproximar o texto da realidade, deforma esta mesma realidade, ou melhor, a reconfigura a partir das particularidades subjetivas: [...] "Costumo buscar essa forma (literária) pela constituição de um (outro) mundo e de uma [outra] visão de mundo" (op. cit., p. 217).

Esta inclinação de Bernardo Carvalho para fazer de sua literatura um gesto de desvio ou reconfiguração "aberrante" da ordem se justifica pela maneira como ele compreende a constituição do panorama literário brasileiro. De forma crítica, Bernardo Carvalho afirma que "[...] no Brasil, é comum tratar a literatura como documento histórico ou sociológico" (op. cit., p. 217 218). Segundo Carvalho, as razões estariam ligadas a fatores como as carências sociais brasileiras, que funcionariam como mecanismo de pressão sobre a 
produção cultural para que se valorize uma concepção sociológica e documental de literatura em detrimento de outras modalidades:

[...] Passa a ser considerada desprezível a literatura na qual não se reconhece de imediato a sociedade ou o momento histórico, a ponto de muita gente não perceber mais que a literatura já é o momento histórico, ou melhor, que ela também faz o momento histórico, e não apenas o fotografa. É essa, no fundo, a graça de toda criação que se preza (op. cit., p. 218).

Esse aspecto do não reconhecimento fácil da sociedade brasileira na narrativa é um fator fundamental a ser considerado em relação aos romances de Bernardo Carvalho. $\mathrm{O}$ contexto social e histórico brasileiro não aparece como um dado central nessas narrativas, mas como uma dimensão relativa a outros contextos. As imagens constituídas sobre o Brasil, em suas obras, aparecem de maneira indireta. Nesse sentido, as expectativas de leitura, principalmente fora do Brasil, em relação a uma literatura brasileira cuja trama acontece, por exemplo, na Mongólia, nos Estados Unidos, ou em São Petersburgo, são frustradas. No contexto de recepção dessas obras no Brasil, o valor que elas trariam, e é isso que Bernardo Carvalho sugere, é o de não cair na armadilha da instrumentalização política da literatura, em detrimento do seu caráter de produção criativa. É nesse sentido que suas obras se desviam de ambas as expectativas, e constroem o seu lugar de enunciação a partir de uma perspectiva de que a liberdade de criação é o principal gesto político que a literatura poderia constituir.

Bernardo Carvalho não se alinha a uma literatura de cunho estritamente realista, muito menos a uma concepção "beletrista" da literatura. Segundo Carvalho, no Brasil, em função do baixo índice de leitura e do alto nível de injustiça social, a produção cultural é pressionada a conceber a literatura como um modo de dar "voz às ruas". Na concepção de escritores como Bernardo Carvalho, por exemplo, essa busca por um autêntico reificado produziria um tipo de literatura que "passa a ser sinônimo da verdade, de engajamento político e de justiça social, sobretudo nos momentos em que a injustiça e a desigualdade se tornam mais escandalosas e estarrecedoras" (CARVALHO, 1996, p. 217). Bernardo Carvalho faz uma observação que, de uma certa forma, se alinha a uma posição discursiva que vê na literatura um papel diferente de uma concepção naturalista da arte. Esta oposição que Bernardo Carvalho nos sugere acima estaria embasada na percepção de que, na maioria dos casos, o resultado daquilo que se produz com as boas intenções seria uma mistificação do outro, que não resolveria a problemática da injustiça nem tampouco se constituiria numa literatura como criação de uma realidade.
Seria fundamental fazer uma ressalva em relação à posição de Bernardo Carvalho sobre a necessidade de revelação da realidade, de denúncia das injustiças sociais e dos processos de violência a que a sociedade brasileira está exposta. Em suas próprias palavras, encontramos a seguinte reflexão:

[...] É importante deixar bem claro que não me oponho (nem poderia) à manifestação da realidade, da violência, dos oprimidos e dos injustiçados na literatura. Até porque, de certo modo, é isso o que a literatura na qual acredito manifesta ao criar diferenças e desvios. Ela amplia a realidade. Abre novas possibilidades de compreensão da realidade, em vez de se contentar com uma só, consensual, majoritária. Mas é difícil engolir a impostura que pretende que uma determinada manifestação literária seja imediata e espontânea, e por isso mais verdadeira, pois seria aceitar o retrocesso proposto por quem subjuga a literatura, em última instância, ao relato, ao depoimento, ao documental, como se a invenção fosse secundária. Tudo em literatura é criação, do aparente documento à ficção mais inverossímil (op. cit., p. 219).

A disputa de concepções do literário que Bernardo Carvalho aponta nesta passagem marca um antigo debate na cultura brasileira sobre o lugar da arte na sociedade. Como já se referira anteriormente, Carvalho está consciente das pressões que se realizam sobre quem produz literatura em um país que até bem pouco tempo atrás tinha um dos maiores índices de analfabetismo da América Latina. Diante de um quadro social e intelectual deste tipo, qualquer literatura que, em vez de retratar a realidade (em função de facilitar o processo de identificação), escolhe reconfigurar a realidade, corre o risco de ser acusada de inautêntica, alienada e elitista. No caso de Bernardo Carvalho, é este desvio, ou desencanto, como ele prefere chamar, que mobiliza a sua escrita:

[...] O desencanto com esse tipo de naturalismo militante ou oportunista está de alguma maneira na origem dos meus livros. Todos eles dão a entender, de um jeito ou de outro, que vivemos num mundo cujo entendimento é sempre uma convenção, que parece dar sentido a tudo, quando no fundo é apenas um artifício cambiável. É essa a sua militância: as convenções são criadas pelas necessidades do mundo; cabe aos homens criar novas necessidades e refletir sobre elas, pela ciência e pela arte, em vez de apenas espelhá-las e satisfazê-las (op. cit., p. 219).

Bernardo Carvalho faz eco, aqui, a uma concepção de arte que reconfigura a noção de intervenção política da literatura. Intervenção deve ser entendida aqui de forma bastante modesta e limitada. Ela não passaria pela construção de uma plataforma política institucionalizada, 
mas pela constante batalha de pensar e repensar as nossas formas de entendimento. $\mathrm{Na}$ análise que será realizada mais adiante sobre Nove noites, apontarei para o modo como a problemática da reconfiguração da realidade passa necessariamente pela construção de narradores conscientes do poder da linguagem como força desconstrutora da realidade política e social, mas também como força criativa, que promove desvios na tradição e nas práticas reificadas.

\section{Olhares cruzados}

Em agosto de 1939, o jornal The New York Times publicou a seguinte nota de falecimento:

RIO DE JANEIRO, Brazil, Aug. 18. - Paul Ramos, Federal Governor of the State of Maranhao, reported to the United States Consul here today that Buell Quain, anthropology student from Columbia University, had hanged himself on Aug. 2. United States official had requested an inquiry after Indians who accompanied Mr. Quain reported he had hanged himself after they had prevented him from ending his life by slashing his wrists. Manuel Perna, who was Mr. Quain's agent in Carolina, a village in Maranhao, said the explorer was greatly depressed late in July when he received a batch of letters. Mr. Perna reported that the letters had "bad news", according to Mr. Quain. The letters were burned. It was reported he had complained about domestic difficulties. Joao, his chief Indian guide, declared that after reading the letters Mr. Quain became ill, that on the night of Aug. 2 he wrote many letters, weeping while writing. ${ }^{3}$

É exatamente em torno do mistério da morte do antropólogo americano Buell Quain (1912-1939) que o romance de Bernardo Carvalho se organiza. Nove noites é um romance que pretende narrar o processo de investigação da morte do antropólogo americano Buell Quain, que se suicidara "na noite de 2 de agosto de 1939, aos vinte e sete anos" (CARVALHO, 2002, p. 7), no estado do Mato Grosso, quando realizava suas pesquisas

\footnotetext{
"Buell Quain Suicide Verified by Brazil". The New York Times. 19 Aug. 1939. "RIO DE JANEIRO, Brasil, agosto 18 - Paulo Ramos, Governador do Estado do Maranhão, informou ao cônsul dos Estados Unidos aqui hoje que Buell Quain, estudante de antropologia da Universidade de Columbia, se enforcou no dia 2 de agosto. Os oficiais americanos solicitaram um inquérito depois que os índios que acompanhavam Buell Quain relataram que ele se enforcou depois de o terem impedido de terminar sua vida cortando os pulsos. Manuel Perna, que era o representante de Buell Quain em Carolina, uma aldeia no Maranhão, disse que o explorador estava muito deprimido no final de julho, quando recebeu um lote de cartas. Manuel Perna relatou que as cartas continham "más notícias", de acordo com Buell Quain. As cartas foram queimadas. Foi relatado ainda que ele havia reclamado sobre dificuldades domésticas. João, seu guia indígena, declarou que depois de ler as cartas, Buell Quain ficou doente, e que, na noite de 2 de agosto, ele escreveu muitas cartas, chorando enquanto escrevia" (tradução minha).
}

de campo na aldeia dos índios Krahô. A narrativa ancorase neste fato real para ficcionalizar as possíveis razões do suicídio.

O romance se estrutura em torno de diversas vozes narrativas: um jornalista sem nome que, no início do ano de 2001, toma contato com a notícia do suicídio do estudante de antropologia, fica impressionado com o fato e resolve investigá-lo, e Manuel Perna, engenheiro aposentado que se tornara amigo de Buell Quain. A narrativa está permeada também por vozes de várias pessoas que tiveram algum contato com Buell Quain: os dois índios que o acompanhavam quando ele se suicidou, em uma das nove noites que levaria para realizar o percurso entre a aldeia dos índios e a cidade mais próxima, Carolina, no Estado do Maranhão; os depoimentos e cartas de familiares, colegas e professores; e, elemento fundamental, as supostas cartas e notas do próprio Buell Quain. Dentro desta estrutura, o dilema da representação é dramatizado pelas várias perspectivas aduzidas, postas em movimento para recuperar não a verdade, mas uma verdade possível de existência humana.

A narrativa, portanto, revela um mosaico de informações contraditórias e forma um quebra-cabeça intrincado e fragmentado. Formalmente, Nove noites tenta espelhar a própria condição do personagem principal: um sujeito vivendo um estado de dissociação com seu meioambiente original, a vida provinciana e conservadora do meio-oeste americano dos anos 1930. Diante desse não reconhecimento de si e dessa dissociação experimentada, o sujeito não consegue articular facilmente um sentido para a própria experiência, porque esta tornara-se por demais complexa. Nesse aspecto, toda a narrativa é uma tentativa de reconstituir um sentido para a experiência.

Manuel Perna, a voz que abre a narrativa, é constituída como uma das poucas pessoas que convivera com Buell Quain. Sua retrospectiva dos fatos está mediada por uma memória desconfiada:

[...] Não me peça o que nunca me deram, o preto no branco, a hora certa. Terá que contar apenas com o imponderável e a precariedade do que agora the conto, assim como tive que contar com o relato dos índios e a incerteza das traduções do professor Pessoa. As histórias dependem antes de tudo da confiança de quem as ouve, e da capacidade de interpretá-las (op. cit., p. 8).

Já se anuncia acima, pelo menos na construção narrativa estruturada na voz de Manuel Perna, uma consciência que duvida do estatuto de verdade factual de qualquer relato. A base epistemológica de uma consciência deste tipo está na aceitação do pressuposto de que toda representação carrega em si mesma as marcas de uma subjetividade, e que a reconstituição objetiva da 
experiência seria um mito. $\mathrm{O}$ que resta de qualquer evento seriam os fragmentos, as perspectivas reveladas a partir de vozes diferenciadas.

Assumir determinada posição a posteriori, depois de um processo interpretativo dos precários rastros da experiência disponíveis, implicaria, portanto, deslocarse dentro de uma cadeia significativa e aprender com a própria experiência da leitura. Bernardo Carvalho constitui um Manuel Perna que fratura a realidade supostamente factual da narrativa do jornalista que investiga a morte de Buell Quain. Manuel Perna ficara encarregado de guardar as relíquias deste evento (cartas e anotações de Buell Quain) para serem entregues e reveladas para um suposto "você", que tem presença virtual na narrativa e pode ser interpretado como sendo também o próprio leitor que, diante dos elementos que serão dispostos pela narrativa fragmentada de várias vozes, deverá se incumbir da responsabilidade de atribuir algum sentido ao que ler.

Não é coincidência alguma que as primeiras palavras do romance, enunciadas por Manuel Perna, proponham exatamente uma reflexão sobre o caráter dos discursos de verdade:

Isto é para quando você vier. É preciso estar preparado. Alguém terá que preveni-lo. Vai entrar numa terra em que a verdade e a mentira não têm mais os sentidos que o trouxeram até aqui. [...] A verdade está perdida entre todas as contradições e os disparates (op. cit., p. 7).

A investigação sobre o passado não terá, como consequência, a confirmação dos discursos oficiais e das versões canonizadas ou estereotipadas sobre o outro, mas o poder de questionar a herança cultural que constitui a História. Narrar, no sentido que se articula nesse romance, é uma forma de constituir uma possibilidade de entendimento sobre o passado que se oponha aos "fatos que até então terão lhe (ao leitor) parecido incontestáveis" (op. cit., p. 7).

Nesse sentido, a questão do ponto de vista é fundamental em Nove noites. Buell Quain é construído como uma subjetividade em estado de exaustão: “[...] Castro Faria, eu não tenho mais nada a fazer no momento. Já vi tudo" (op. cit., p. 42). O olhar cansado de Buell Quain revela o niilismo e a sensação de trauma que pontua a constituição do sujeito moderno, atravessado pelas catástrofes do século XX. Esta mesma subjetividade niilista aparece resgatada em outro romance brasileiro contemporâneo, Viagem ao México (1995), de Silviano Santiago, ao trazer para a cena a performance do poeta e dramaturgo surrealista francês Antonin Artaud, às voltas com os incipientes nacionalismos fascistas que forneceriam o combustível ideológico para a Segunda Guerra Mundial (1939-1945). Resgatar tais sujeitos funciona como forma de rasurar a ilusão de contentamento que a estrutura ideológica do Estado Novo (um dos contextos políticos de Nove noites) gostaria de propagar, como uma espécie de aposta ingênua no progresso em benefício da racionalidade instrumental.

A inserção de uma revisão dos modos de produção dos discursos fundadores de conhecimento na História é realizada, portanto, a partir de um personagem que representa um deslocamento de rota dentro das formações discursivas que o informam. Em um determinado momento da narrativa, Buell Quain é caracterizado como um indivíduo solitário: "[...] Por que, como os índios, ele (Buell) estava só e desamparado" (op. cit., p. 10). Desamparado do que ou de quem? Muito discretamente, Nove noites propõe uma crítica a uma sociedade constituída cada vez mais sem espaço, sem sensibilidade, sem tempo para a existência de sujeitos que se constituam fora do imaginário racionalista ocidental. Em outras palavras, fora da ordem capitalista.

O olhar de Buell Quain, na percepção que dele tem Manuel Perna, é marcado pelos lugares que visitara. É no olhar de Buell Quain que se percebem as marcas de um sujeito tocado pelo outro e pela diferença que o constitui. Tal diferença é percebida como a expressão do medo, do desamparo e da falta de pertencimento:

[...] Os olhos (de Buell) que traziam o que ele tinha visto pelo mundo, a morte de um ladrão a chibatadas numa cidade da Arábia, o terror de um menino operado pelo próprio pai, a entrega dos que lhes pediam que os levasse com ele, para onde quer que fosse, como se dele esperasse salvação (op. cit., p. 42).

No olhar nômade de Buell Quain, expressamse os sinais das experiências trágicas às quais tivera possibilidade de vivenciar em suas viagens. A sua exposição a tais realidades deixa marcas de um terror impossível de ser representado para aqueles que não passaram pela mesma experiência. A impossibilidade de comunicar o real da experiência trágica do outro, e para um outro, requer um interlocutor capaz de atualizar uma possível compreensão da experiência trágica por meio daquilo que não se diz. Manuel Perna reflete sobre a experiência do outro:

[...] Ele (Buell) me disse que ninguém pode imaginar a tristeza e o horror de ser tomado como salvação por quem prefere se entregar sem defesas ao primeiro que aparece, quem sabe um predador, a ter que continuar onde está. E eu imaginei (op. cit., p. 42).

É em função desse dilema da transmissão da experiência que Klinger (2007) afirma que uma das grandes questões colocadas pelo romance Nove noites é a impossibilidade de "tradução" dos mundos, "a 
incomunicabilidade que resulta do choque cultural" (KLINGER, 2007, p. 145). Klinger faz referência a uma passagem do texto de Borges, El etnógrafo, para marcar essa impossibilidade da tradução. Murdock, aluno de línguas indígenas, depois de uma temporada de pesquisa de campo, e depois de descobrir o segredo dos bruxos da tribo, só revelado aos iniciados, volta à cidade e se recusa a revelá-lo a seu professor. Klinger aproveita esse fragmento do texto de Borges para articular seu argumento de que o paradoxo da cena é que ela consiste na expressão de que "não se pode chegar suficientemente próximo do outro sem se tornar, também, um outro" (op. cit., p. 145). O fracasso na transmissão do segredo acontece pelo fato de o professor não ter passado pela experiência na tribo e ser impossível para Murdock reconstituí-la em palavras para os não iniciados. Há algo na experiência que resiste à representação. O segredo estaria exatamente naquilo que não pode ser representado, apenas vivenciado. Klinger percebe uma impossibilidade comunicativa semelhante em Nove noites. A comunicação interrompida entre Buell Quain e os índios é reativada pelo novo fracasso do jornalista, que visita a aldeia dos Krahô, sessenta e dois anos depois de Buell Quain, na tentativa de descobrir o segredo por trás de seu suicídio.

A construção que se faz de Buell Quain é desenvolvida também a partir da percepção do também intelectual Castro Faria, entrevistado pela segunda voz narrativa (o jornalista), que teria tido uma relação próxima com o antropólogo. A ênfase de Castro Faria no caráter de "miragem" da filosofia que informa a existência excêntrica de Buell Quain, que provoca o seu deslocamento da sociedade burguesa à qual pertencia, amplia esta outra passagem, na qual o narrador jornalista faz referência ao fato de que:

[...] Depoimentos de alunos e colegas atribuem a (Ruth) Benedict (orientadora de Buell na universidade de Columbia) uma preferência por estudantes em desacordo com o mundo a que pertenciam e de alguma forma desajustados em relação ao padrão da cultura americana (CARVALHO, 2002, p. 17).

O gesto de Ruth Benedict, projetado na performance de Buell Quain, cria um contraste explícito com o contexto intelectual brasileiro da época, no qual a pompa, o rigor e o tradicionalismo da cultura intelectual é assinalada, com ironia, logo que Buell Quain chega à cidade de Carolina.

O olhar estrangeiro de Buell Quain funciona para posicionar a cultura intelectual local como um ritual híbrido, estruturado entre uma espécie de aristocracia burguesa de valorização mítica do literário, em terras de analfabetos. $\mathrm{O}$ olhar do estrangeiro, neste contexto, ajuda Bernardo Carvalho a construir uma perspectiva fora do narcisismo etnocêntrico que informa as ideologias nacionalistas. Nove noites, ao não se estruturar como uma narrativa simplificada da realidade, levanta uma suspeita saudável, e não cínica, em relação às formações culturais às quais somos todos subjugados. É nesse sentido que se pode pensar também em Nove noites como um jogo de espelhos recíprocos que promove desvelamentos e questionamentos das percepções que os personagens possuem de si mesmos e do outro. Para os sujeitos com abertura suficiente para este jogo na linguagem, o resultado pode ser o aprimoramento da percepção crítica, requisito fundamental para a formação de sujeitos menos obtusos, em um mundo que tornou a experiência humana mais complexa, em função da diversidade de demandas sociais e de pontos de vista a serem considerados.

\section{Morte como transição paradigmática}

Não é somente a morte de Buell Quain que funciona de modo significativo para sugerir o dilema da representação da experiência. Nove noites é um livro permeado pelo signo da morte: a morte de Buell Quain, principalmente, mas também as do pai do narradorjornalista; do fotógrafo Andrew Palson; de Manuel Perna (que escreve para salvaguardar a memória do que vivera, para o futuro); as mortes inferidas a partir da referência ao episódio de 11 de setembro de 2001 em Nova York.

$\mathrm{Na}$ articulação do signo da morte em Nove noites, sinaliza-se também para a questão da mudança de paradigma que articula a constituição da antropologia estruturalista como ciência: foi com o objetivo de estudar as formas sociais e culturais condenadas à morte pela modernidade que a antropologia se constituiu como uma das ciências do humano. A morte de Buell Quain revela, portanto, a impossibilidade de resgate deste outro antropológico (e da sua reificação em objeto de conhecimento) do processo de transformação a que a modernidade submete as culturas, porque a sobrevivência desse outro só pode ser efetuada a partir dele próprio e das condições concretas que ele possua para se constituir e se perpetuar como cultura.

É nesse sentido que em Nove noites pode-se perceber um alinhamento a uma posição discursiva que afirma a inevitabilidade dos processos de transformação cultural. Em vez da morte das culturas indígenas - que ainda sobrevivem e se adaptam (muito precariamente à modernidade, e é exatamente este o dilema para os Estados modernos, que buscam a implementação de políticas multiculturais para dar conta da aniquilação da diferença), - o que de fato morreu foi o projeto da antropologia estrutural, que Buell Quain representa, de proteger tais formações culturais da inevitabilidade das transformações impostas pela modernidade. $\mathrm{O}$ trânsito e a ruptura de fronteiras são inevitáveis, parece-nos sugerir 
Nove noites. A questão que fica em aberto é a seguinte: em que termos se constitui este processo de mudança e adaptação imposto às culturas locais pelas forças sócioeconômicas que guiam os processos de globalização cultural e econômica? É preciso estar atento para se perceber esta nova economia das relações sociais dentro de uma filosofia multiculturalista e se perguntar a quem de fato esta constituição de "nichos" de diferença reificada realmente interessa.

Em Nove noites, a realidade cultural que se constitui aparece como um espaço de instabilidade e transição, e composto de múltiplas perspectivas em conflito. A realidade brasileira configurada no romance não se oferece ao encontro com o leitor de forma transparente e unívoca. É neste intrincado jogo de linguagem que o leitor se vê interpelado a se encontrar, ou seja, a atribuir um sentido para a experiência de leitura de um texto que não facilita a compreensão. Este exercício epistemológico, em última instância, funcionaria como um modelo de formação da subjetividade aberto para a complexidade dos fenômenos da realidade circundante a que todos somos solicitados a atribuir sentido.

\section{Enraizamentos essencializados e desvios de rota}

Paulo César Silva de Oliveira (2007), em um ensaio de análise de outro romance de Bernardo Carvalho, O sol se põe em São Paulo (2007), afirma que a palavrachave para uma boa parte da literatura contemporânea é "errância" (OLIVEIRA, 2007, p. 1). Os exemplos que ele cita são Caio Fernando Abreu, João Gilberto Noll, Chico Buarque e Bernardo Carvalho.

No caso específico de Bernardo Carvalho, Oliveira aponta a ironia e o mosaico de vozes narrativas (que constituem versões antagônicas e complementares dos mesmos fatos) como as estratégias fundamentais para marcar um gesto discursivo de deslocamento em relação a formas uniformizadoras e totalizadoras de constituição da história, do sentido e do próprio ser humano. O lugar de enunciação de Bernardo Carvalho, inserido dentro de uma sociedade de herança autoritária como a brasileira, funciona como um mote para o desejo de errância, entendido aqui como desejo de se constituir fora de uma herança cultural autoritária e baseada na desigualdade. Esta percepção errática que se atribui a Bernardo Carvalho é o que lhe permite se posicionar discursivamente de forma crítica em relação à formação cultural brasileira. Seu lugar de enunciação se estrutura por meio da articulação de estratégias narrativas que fazem uso do "disfarce, jogo, máscara, superposição de narradores e histórias, verdades reveladas que ao serem reveladas provocam mais suspeitas" (op. cit., p. 2). Esconder-se por trás de tantos artifícios de linguagem é uma maneira não de apagar o comprometimento político do autor, mas afirmar este compromisso de modo menos simplista e menos totalitário.

Segundo Nelson Vieira (1991), o uso de uma consciência metaficcional na escrita funciona como mecanismo de confrontação da autoridade por meio de um discurso literário que revela o processo também ficcional dos discursos de verdade. É por meio do exercício da liberdade para a desmistificação das ilusões presentes em várias dimensões da política e da cultura que os escritores brasileiros que praticam a metaficção buscam reduzir a distancia entre arte e vida e estimular seus leitores a se tornarem conscientes dos diversos códigos discursivos. Tais autores estão interessados em alertar sobre os mecanismos de construção discursiva da autoridade, de forma a provocar uma compreensão dos mecanismos narrativos das instâncias autoritárias (VIEIRA, 1991, p. 83).

Esse exercício de desmistificação aparece em Nove noites por intermédio de Manuel Perna. Na voz de Manuel Perna, percebe-se a inversão do mito do espaço paradisíaco associado às formações culturais ligadas à natureza: "[...] Posso não ter imaginado o paraíso, mas o inferno eu pude ver. O pesadelo é um jeito de encarar o medo com olhos de quem sonha. Quando me falava dos Trumai, eu o ouvia falar do medo" (CARVALHO, 2002, p. 49).

O medo que Manuel Perna detecta como sobra representativa da cultura indígena é revelado nos desafios contemporâneos imputados aos Krahôs: as relações às vezes amistosas, muitas vezes violentas entre as tribos da região; a constante ameaça de invasão das terras indígenas pelos fazendeiros da região; o processo de aculturação, que desmantela o modo operacional da cultura indígena, sem que lhe seja proporcionada condições alternativas de rearticulação. A duplicidade do olhar continua também no registro do narrador jornalista:

[...] Buell Quain havia acompanhado o pai em viagens de negócios. Quando tinha catorze anos, foram a uma convenção do Rotary Club na Europa. Visitaram a Holanda, a Alemanha e os países escandinavos. E daí em diante nunca mais parou de viajar. Mas se para Quain, que saía do meio-oeste para a civilização, o exótico foi logo associado a uma espécie de paraíso, à diferença e à possibilidade de escapar ao seu próprio meio e aos limites que lhe haviam sido impostos por nascimento, para mim as viagens com o meu pai proporcionaram antes de mais nada uma visão e uma consciência do exótico como parte do inferno (op. cit., p. 64).

Aqui, como em outras passagens do romance, se estabelece um paralelismo de perspectivas contraditórias e antagônicas sobre uma mesma experiência: o significado 
da viagem. Para Buell Quain, a viagem significaria o encontro com um exótico associado a uma visão do "paraíso", de valorização da diferença e à possibilidade de escapar do provincianismo do meio-oeste americano. Deslocar-se para a Europa, quando criança, constituíra um sujeito inserido em um mundo moderno, no qual as relações intersubjetivas entre os indivíduos poderiam ser vivenciadas como uma experiência de linguagem. Para o narrador, entretanto, a experiência da viagem com o pai para o Xingu constituíra em seu imaginário numa percepção do exótico como o "inferno". O movimento de atribuição de sentido é o oposto aqui. Socializado dentro da complexidade das relações urbanas, o narrador, deslocado para um mundo de relações sociais mais rígidas, se vê completamente desconfortável em tal ambiente.

A passagem marca, assim, o desencontro dos olhares que modalizam os processos de identificação. Este processo de identificação está subordinado a elementos contextuais e à história prévia dos indivíduos, além de elementos inconscientes que não podem ser controlados. Nesse sentido, a promoção de uma abertura para a aceitação de pontos de vista diferenciados e uma capacidade de autocrítica sobre sua própria perspectiva é a base do projeto ético e estético das obras de Bernardo Carvalho.

No contexto sócio-histórico específico de Nove noites, por exemplo, o leitor se depara com dois cenários diferentes, mas ao mesmo tempo semelhantes em sua necessidade de abertura política para a diferença: nos anos 30 no Brasil, durante o Estado Novo, e no início do século XXI, logo depois dos ataques ao World Trade Center, em 11 de setembro de 2001, em Nova York. Em Nove noites, o leitor é solicitado a perceber a sutil relação entre as formas de intransigências políticas e culturais desses dois momentos históricos paradigmáticos: nos anos 30 no Brasil, as implicações do legado de manutenção das injustiças sociais do projeto populista e nacionalista do Estado Novo; nos anos 2000, o dilema para a implementação de uma política multiculturalista e democrática.

É pela voz de Castro Faria que os leitores são situados em uma crítica à política da agência do Estado Novo, responsável pela proteção das populações indígenas:

[... No tempo do Rondon, havia toda aquela ideologia de não tocar em índio, de não ter relações sexuais com os índios, de morrer se preciso fosse, matar nunca. Havia muitos erros do Serviço de Proteção aos Índios nesse tipo de contato. Deve ter pesado muito o fato de ele ser um estrangeiro. Pode ser que na ideologia do SPI, que era de um purismo tolo, fosse melhor ele ser casado (op. cit., p. 38).

A voz de Castro Faria nos ajuda a marcar duas posições discursivas distintas em relação à política do governo
Vargas frente aos índios. A primeira, assumida pelo órgão governamental encarregado de implementar as políticas públicas relativas a essas populações, se constituíam a partir da proteção paternalista. As condições sóciohistóricas que engendraram a ação da filosofia política por detrás do Serviço de Proteção aos Índios são conhecidas de todos: as populações indígenas no Brasil, bem como na América Latina como um todo, sofreram diversas formas de "abusos" a partir do contato com estrangeiros. Essas populações sempre estiveram mais vulneráveis a doenças, por não terem imunidade para reagir a vírus e a bactérias exógenas. A questão fundamental, na passagem acima, parece ser o dilema do protecionismo paternalista que gera políticas nacionalistas. O envolvimento com o outro, na visão do SPI e do Estado Novo, parece colocar em risco uma política nacionalista de proteção do patrimônio material e cultural da nação. Este é um dilema que sempre esteve diretamente inserido no debate sobre a formação dos Estados nacionais nas sociedades pós-coloniais.

Bernardo Carvalho constrói um Buell Quain posicionado discursivamente contra o projeto filosófico positivista e suas implicações dentro do sistema educacional brasileiro da época e como base de sustentação ideológica da política indigenista do Estado Novo:

[...] Numa das cartas que mandou a Margaret Mead, escrita em 4 de julho de 1939, Quain dizia o seguinte: 'O tratamento oficial reduziu os índios à pauperização. Há uma crença muito difundida (entre os poucos que se interessam pelos índios) de que a maneira de ajudá-los é cobri-los de presentes e 'elevá-los à nossa civilização'. Tudo isso pode ser atribuído a Augusto Comte, que teve uma enorme influência na educação superior local e que, através do seu espetacular discípulo brasileiro, o já velho general Rondon, corrompeu o Serviço de Proteção aos Índios. Ainda não consegui estabelecer a conexão lógica, mas sei que ela existe' (op. cit., p. 66-67).

A figura do Marechal Rondon, o militar brasileiro responsável pelas expedições de exploração da Amazônia nas primeiras décadas do século XX, aparece como sendo o herdeiro intelectual e o maior expoente do pensamento positivista brasileiro. A oposição que Buell Quain representa está constituída a partir de uma visão que irá informar a antropologia como uma ciência interessada em romper com os determinismos biológicos como critérios de análise das culturas ou grupos humanos que dominaram o pensamento sociológico do século XIX. No Brasil, seus representantes principais foram Nina Rodrigues (18621906), Oliveira Viana (1883-1951), Euclides da Cunha (1866-1909) e Sílvio Romero (1851-1914).

A primeira tentativa da antropologia brasileira de rompimento com o determinismo racial para a explicação das diferenças entre os grupos humanos acontece no 
Brasil a partir de Gilberto Freyre (1900-1987), com Casa-Grande \& Senzala (1933). Gilberto Freyre escrevera Casa-Grande \& Senzala sob a influência da escola de antropologia cultural da Universidade de Columbia, a mesma escola à qual estava vinculado Buell Quain quando estudava no Brasil em 1939.

Bernardo Carvalho, no início do século XXI, consciente da malha discursiva que envolve a relação da antropologia com o Brasil, monta um teatro de posições discursivas, como também o fez Silviano Santiago, em Viagem ao México (1995), usando Antonin Artaud como personagem principal. Qual a finalidade deste teatro? Nove noites se revela como um livro interessado em marcar um território discursivo cujo projeto ético seria o de não transformar a relação com o outro em uma dicotomia maniqueísta. $\mathrm{O}$ outro aparece neste romance situado historicamente, gesto este que possibilita projetar uma forma de compreensão sobre as motivações e contingências de sua constituição.

Nove noites se posiciona em relação ao debate sobre o multiculturalismo de forma desconstrutiva. A concepção de cultura articulada no romance questiona as modalidades culturais baseadas em essencialismos ontológicos. A partir da dramatização da impossibilidade de representar o outro de forma transparente, o romance desconstrói os pressupostos epistemológicos de um pensamento essencialista que tenta dar forma às diferenças culturais por meio da reificação do outro. O jogo de múltiplas perspectivas que forma a organização estrutural da narrativa coloca em discussão os modelos de percepção que formam uma determinada realidade. Assim como o narrador jornalista de Nove noites desiste de fazer uma reportagem objetiva sobre o suicídio de Buell Quain (resolvendo, ao contrário, escrever um romance), o narrador do romance seguinte de Bernardo Carvalho, Mongólia (2003), confessa, no final da narrativa, que apenas organizou as diferentes perspectivas em jogo no romance, e a elas inseriu a sua opinião. Como resultado deste processo de disputa pelas versões dos fatos, o leitor é interpelado a associar-se àquela perspectiva que lhe parecer mais coerente. Nestes dois romances, a voz do narrador não se constitui de forma onisciente, como no romance realista tradicional. A sua perspectiva se constitui como mais uma no jogo de relações de olhares cruzados que a narrativa apresenta. Os romances de
Bernardo Carvalho promovem, assim, uma opacidade na representação da diferença cultural, como forma de sinalizar que o conhecimento que adquirimos sobre a cultura do outro é muito menos transparente do que os discursos de saber gostariam de admitir.

\section{Referências}

CARVALHO, Bernardo. Nove noites. São Paulo: Companhia das Letras, 2002.

CARVALHO, Bernardo. Onze. São Paulo: Companhia das Letras, 1995.

CARVALHO, Bernardo. Os bêbados e os sonâmbulos. São Paulo: Companhia das Letras, 1996.

CARVALHO, Bernardo. Teatro. São Paulo: Companhia das Letras, 1998.

CARVALHO, Bernardo. As iniciais. São Paulo: Companhia das Letras, 1999.

CARVALHO, Bernardo. Medo de Sade. São Paulo: Companhia das Letras, 2000.

CARVALHO, Bernardo. Mongólia. São Paulo: Companhia das Letras, 2003.

CARVALHO, Bernardo. O sol se põe em São Paulo. São Paulo: Companhia das Letras, 2007.

CARVALHO, Bernardo. O filho da mãe. São Paulo: Companhia das Letras, 2009.

CARVALHO, Bernardo. Minha cegueira. In: Literatura e Sociedade, n. 8, São Paulo: USP/FFLCH/DTLLC, 1996, p. 217-219.

OLIVEIRA, P. C. S.; NITRINI, Sandra Margarida (Orgs.). Que narrativa, que história? Sobre a errância na prosa de Bernardo Carvalho. Anais do XI Encontro Regional da ABRALIC 2007. São Paulo: Universidade de São Paulo/ABRALIC, 2007. p. 1-10.

KLINGER, Diana Irene. Escritas de si, escritas do outro: o retorno da virada etnográfica: Bernardo Carvalho, Fernando Vallejo, Washington Cucurto, João Gilberto Noll, César Aira, Silviano Santiago. Rio de Janeiro: 7Letras, 2007.

SANTIAGO, Silviano. Viagem ao México. Rio de Janeiro: Rocco, 1995.

VIEIRA, Nelson H. Metafiction and the Question of Authority in the Postmodern Novel from Brazil. Hispania, v. 74, n. 3, 1991. 